\title{
The achievement of food and nutrition security in South Asia is deeply gendered
}

Nitya Rao

Professor, Gender and Development

School of International Development

University of East Anglia

Norwich NR4 7TJ, UK

n.rao@uea.ac.uk

\begin{abstract}
Women form an integral part of the agricultural sector, and in much of South Asia women make up a majority of the agricultural workforce, often compelled to work in order to meet their families' basic needs. While their contributions are recognised as central to the food and nutrition security of households and communities, their work is not recognized or supported adequately by public policy and social institutions. Women continue to face inequality across key development indicators including health, education, and nutrition; discriminatory laws; and high levels of precarity in terms of income, employment conditions, safety and wellbeing. Social structures that promote gender inequality and inhibit the agency of women contribute to the South Asian enigma - the persistence of undernutrition despite economic growth - and must be addressed to achieve food and nutrition security.
\end{abstract}

Twenty-five years have passed since the Fourth World Conference on Women in Beijing. This was a landmark event for setting in place a comprehensive global policy framework on women's rights and gender equality and giving a fillip to feminist mobilisation and alliance-building within countries and transnationally. The record of success over the intervening years has been ambivalent. Progress has been made in education, life expectancy and political participation, including quotas for women in local councils, legislation on domestic violence and inheritance rights. Yet, laws are rarely enforced, and gender inequalities have deepened across sectors in many parts of the world including South Asia ${ }^{1}$. This Perspective posits that gender inequalities and the social structures that support them, specifically in the agri-food sector, underpin persistent food and nutrition insecurity in South Asia and deserve greater policy and law enforcement attention.

The South Asian enigma

Despite economic growth, food and nutrition security has not improved in South Asia, a trend commonly referred to as the South Asian enigma. South Asia continues to be placed in the 'serious category' by the Global Hunger Index, with India performing worse than its neighbours, with the sole exception of Afghanistan². Poor child nutrition outcomes in South Asia are generally seen to result from proximal causes such as poor infant and young child feeding practices, poor nutrition among women before and during pregnancy, and poor sanitation practices ${ }^{3,4}$. However, there are multiple contextual drivers relating to gender that contribute to the South Asian enigma - the underlying social structures that support inadequate nutrition through the suppression of women's agency. In addition to the question of female survival itself, resulting from sex selection before birth, labour market arrangements that devalue women's work and perpetrate gender wage gaps ${ }^{5}$, unequal access to productive assets ${ }^{6}$, and growing incidents of violence against women ${ }^{7}$, all contribute to this 
enigma. These vary across agro-ecologies and farming systems, and by household social and economic status ${ }^{8}$.

\section{Violence and risk of food and nutrition insecurity}

Violence against women is a structural barrier to the attainment of food and nutrition security through a range of pathways: withholding food or restricting funds to purchase food ${ }^{9}$; controlling when and how they eat ${ }^{10}$, pushing women into high-risk behavior to secure money for food ${ }^{11}$, or the normalization of physical violence related to the non-performance of food-related work (food production, shopping, cooking etc) ${ }^{12,13}$. While food deprivation itself is a form of violence, it can at the same time aggravate other forms of violence including early marriage and trafficking of young girls or intimate partner violence.

Violence occurs through the life-course ${ }^{14}$. In India, despite legislation such as the Preconception and Prenatal Diagnostic Techniques Act passed in 1994 to prevent sex-selective abortions, child sex ratios continue to decline, from 927 girls to 1000 boys in 2001 to 919 in $2011^{15}$. The growth in the Indian economy over this period has not helped reverse this trend, though if the girl child survives, she is likely to receive equal opportunities, at least in schooling, partly also a result of affirmative action including the recent policy campaign to 'educate and save the girl child' (beti padhao, beti bachao $)^{1}$. Once she reaches adulthood, different forms of domestic violence, including dowryrelated harassment, again take centre-stage, despite the existence of laws to protect women ${ }^{16}$.

In fact, specific campaigns to empower women, including financial inclusion through self-help groups or support for secondary education of girls, appear to be evoking a violent backlash, intensifying in the process varied forms of 'food violences' ${ }^{17,10}$. With an incidence of roughly 40 per cent, the experience of physical violence is particularly severe for women from rural areas, belonging to the Scheduled Castes and Tribes, also amongst the lowest wealth quintiles and least educated. In the absence of law enforcement, such forms of violence have consequences for wellbeing in general, and the nutritional status of women and their children in particular ${ }^{18,19}$. Roughly one in every two women in South Asia suffered from anaemia in 2016, much higher than the global average of one in three women (World Bank, https://data.worldbank.org/indicator/SH.ANM.ALLW.ZS), with the proportion of anaemic women higher in the lowest wealth quintiles (58 per cent), in rural areas (54 per cent), and amongst the Scheduled Castes ( 56 per cent) and Tribes (60 per cent). The same trend holds for men, though much lower than for women (32 per cent in lowest wealth quintile and 25 per cent in rural areas) ${ }^{16}$.

The overlap of violence and poor nutrition, in the above case anaemia, has implications for birthweight, stunting and wasting of children under five years. Amongst the Scheduled Tribes and Castes, over 2 in 5 children continue to be stunted and 1 in 5 wasted and of low birth weight, as against 1 in 5 stunted children amongst the higher wealth quintiles and general classes. Nutritional surveys among tribal groups in India between 1985-2008 point to a secular decline in dietary diversity $^{20}$, reflecting persistent structural violence against these communities ${ }^{21,4}$. In many of these contexts, the cultivated staple grain used to be supplemented by greens, roots, tubers, fruits and fish, secured from rivers and ponds, forests and common lands, that ensured dietary diversity. Such collection tasks are now severely constrained by women's time poverty ${ }^{22,23}$, intensified by the lack of infrastructure and services, but also by growing restrictions on these 'common' spaces with the rapid privatization of nature ${ }^{24,25}$. Despite some improvements over the past decade in India, the

\footnotetext{
${ }^{1}$ Launched in January 2015 by the Government of India, it seeks to address the issue of declining child sex ratios in the 100 worst-affected districts, primarily in northern India.
} 
nutrition situation nevertheless remains serious in rural areas, especially amongst communities dependent on agriculture and food production for their livelihoods.

\section{Resilience of food systems is deeply gendered}

Why are rural women and men, especially those dependent on farming, the worst off in terms of nutrition and food security outcomes? Several explanations can be found for this paradox, including the lack of adequate attention to agricultural growth and development in states and districts revealing a high nutrition burden, through appropriate investments in research, extension, skill-building, and infrastructure, in particular, ensuring water and land security to the majority of small and marginal holders ${ }^{26}$. Resilience of food systems depend on political, economic and social relations, and these are all deeply gendered. The most marginal groups in India, the Scheduled Tribes and Scheduled Castes, are caught in cycles of indebtedness, increasing in severity due to both climate variability and market unpredictability - a phenomenon described by Watts ${ }^{27}$ as 'silent violence'. Coping in such contexts reflects positions of structural (dis)advantage and the presence/absence of support systems.

Mechanisation and displacement: Technological interventions, in particular the mechanization of transplanting, weeding and harvesting, all female labour-intensive activities, while largely bypassing remote rural areas, especially those occupied by the Scheduled Tribes in India, have simultaneously led to the displacement of female hired labour, belonging to the landless Scheduled Castes, and other marginal farming households. The impacts of mechanization are clearly differentiated - while some women have lost work and incomes, others are potentially engaging in more unremunerated work as family labour and are increasingly time-poor ${ }^{28,29}$.

Welfare measures and dietary diversity: While the national government has not strengthened the agricultural sector through better prices, assured procurement or investments in climate-proofing ${ }^{30}$, several state governments in India have sought to ameliorate rural distress and other related effects of agrarian stagnation through welfare measures. Leaders in this respect are the states of Tamil Nadu and Andhra Pradesh with 55 and 48 welfare schemes respectively. These include the provision of free rice through the universal public distribution system, mixer grinders and limited units of free electricity to reduce the drudgery of domestic labour, and maternity entitlements in both cash and kind ${ }^{31,32}$. While these measures have clearly contributed to food security, the lack of income in the hands of women agricultural workers has meant restrictions on dietary diversity, and in turn, nutrition security ${ }^{4}$.

Gender segregation, lack of recognition and entitlements: Given the gender segregation of labour markets and the wage gaps therein, it is usually men who migrate out of rural areas in search of work. A majority confront poor living and working conditions in migrant destinations, and often return home sick. Considerable portions of their earnings are spent on health expenses. At the same time, their bodies need time for recovery and they are unable to return to work soon ${ }^{33}$. Women left behind with the responsibility for managing agricultural work on family farms, classified as 'unpaid household helpers' in Indian statistics, receive no income, are usually over-worked and have no wage-linked benefits ${ }^{34}$. Apart from agricultural work, household work and child and elder care responsibilities remain assigned to women within existing gender divisions of labour ${ }^{35}$, with the additional task of now caring for their men. Overburdened with productive and reproductive work, alongside the lack of recognition and entitlements as farmers in their own right, has pushed women further into relationships of dependency ${ }^{12}$, whether with their husbands, traders, contractors and moneylenders, or state offices responsible for welfare provision. Such dependency contributes to the experience of both direct and indirect forms of violence and harassment, whether it be repeated visits to beg dominant men for cash advances, or the granting of sexual favours in return for receiving fair wages ${ }^{36}$, or simply carrying additional burdens of work. 
Agricultural work in the present context is then unable to ensure adequate food, incomes, or indeed time for the performance of caring and nurturing tasks, central to nutrition security. This has adverse impacts on women's own health and child and household nutrition ${ }^{37,8}$. What is needed is the creative use of technologies, including digital platforms and mobile telephony, to enable women access to information, skills, resources and inclusion in local governance - an opportunity structure that can enable the exercise of agency by women and the poor, including representation and voice in key decision-making arenas ${ }^{38}$. There is evidence to suggest that women's participation in local government (panchayats) can contribute to improved consumption alongside wider development benefits ${ }^{39}$.

\section{Access to resources and opportunities}

In rural contexts, evidence from India and other parts of South Asia, reveals that successful engagement with higher-return, non-agricultural or agricultural enterprises results from the ownership of land and other assets (such as wells for irrigation, or farm equipment) ${ }^{31}$. Rural women are less likely to be in a position to control productive resources necessary for agriculture in intensely patriarchal contexts and are more restricted in their access to and control over land, energy, water, pasture, forests, agricultural inputs, credit and insurance services, information, technology and markets ${ }^{40}$. Despite progressive legislation in relation to inheritance of agricultural land in India, and credit policies that target women's self-help groups across the subcontinent, without mechanisms for enforcing rights, existing gendered power hierarchies ensure that such laws and policies are not operationalized $^{6}$. On the contrary, there is a greater policing of women's mobility and marriage options ${ }^{41}$. This is because assets are not just material resources with impacts on wellbeing, but are a source of power, symbolizing gendered meanings and identities. Given the social expectation of men as 'providers', land and money are constructed as 'male' assets, so a woman making claims to them can be seen as deviating from the norm of a 'good woman', justifying a violent backlash?

Statistical data, measuring gender gaps in landholding, employment, and education, since the 1970s, reveals a slight, but not necessarily significant, change over time. Lack of land titles is clearly a problem for women in terms of accessing credit and other resources, specifically from formal institutions, such as banks and agricultural cooperatives. Yet field studies seem to indicate that both men and women view household land as joint property, irrespective of who holds the title. In the context of male migration, men are generally supportive of their wives claims to land; women perhaps are more cautious, cognizant of the need for community recognition, social legitimacy and support ${ }^{42,34}$. However, if the marriage breaks down, due to death or separation, they do demand a share of land widows in India constitute the largest proportion of women landowners ${ }^{43}$.

What seems significant here is the introduction of gender-specific incentives and entitlements alongside grassroots mobilization and collective action to claim these resource rights and benefits ${ }^{44}$. The guaranteed right to 100 days of work under the Mahatma Gandhi National Rural Employment Guarantee Act, 2005, or 25 kilograms of foodgrains per month under the National Food Security Act, 2013, in India, and the mobilization around these, have provided women with opportunities for bargaining within households and communities. While cereal consumption now appears to be adequate, nutrition security remains a harder goal to reach.

Apart from changing aspirations within household consumption patterns, attaining the goal of nutrition security is equally dependent on state provisioning of clean drinking water, sanitation and reliable health services. Sanitation, in the Clean India Campaign (Swachh Bharat Abhiyan), is interpreted as universal access to toilets. While this is undoubtedly important, insufficient attention has been paid to the disposal of solid and liquid waste, contributing to the growing burden of infectious diseases ${ }^{45}$. Similarly, while universal health insurance (Ayushman Bharat) may support 
curative care, primary health care provisioning, key to disease prevention, remains weak. The responsibility for both health and nutrition security is now placed on low paid and poorly trained women community health and nutrition workers, with little power in their local, rural context ${ }^{5}$. Rather than devaluing their work and time, often with negative consequences even on their own health, they need to be adequately supported to perform their roles, both through skill-building and the strengthening of referral and back-up health services.

\section{Gender inequalities underpin the achievement of food and nutrition Security}

While lack of food can itself be understood as a form of structural or 'silent' violence, or can provoke violence, experiences of violence can also restrict women's mobility and ability to work and produce food. Central to understandings of food security then is an understanding of gendered power relations, yet extant debates, while focusing on availability, access, adequacy and absorption ${ }^{46}$, fail to recognize the social and gender dynamics underpinning the achievement of food and nutrition security, intertwined at the household level, with emotions of love and fear, cooperation and conflict. While in instances of severe male domination, the idea of 'singlehood for security' ${ }^{47}$ could prevail, combining economic security with a lower risk of violence, women in general are not necessarily looking for autonomy, rather a degree of relational mutuality and reciprocity.

What becomes clear is the need to move beyond the binaries of women and men, to look at gender as a relational, and therefore, dynamic construct ${ }^{6,35}$, shifting in response to changes in the policy context, labour market signals and household and community level needs and aspirations. While gender relationships signify unequal power, they also alert us to the exercise of everyday agency, the negotiations involved in survival with dignity ${ }^{48}$. Research needs to focus much more on fine-grained analysis of contextual factors that mediate gender relations and food and nutrition security, be it the time and intensity of agricultural work across seasons and cropping patterns, prevailing labour market and childcare arrangements, household socio-economic status, the nature of male contributions to household survival, or the mechanisms for inclusion/exclusion in claiming rights and benefits, including social protection and welfare measures seeking to enhance women's agency and bargaining position. Such an exploration provides insights into potential entry-points for policy that can contribute to positively alter the contexts that constrain choices available to poor rural women, and men.

A gender-just food and nutrition security strategy would then involve recognizing women as farmers and producers and strengthening their entitlements ${ }^{49}$, while at the same time enhancing male responsibility for sharing the burdens of both production and reproduction ${ }^{50}$. A partial equilibrium analysis, focusing only on food or nutrition security, or the intensity of agricultural work, will not solve the problem. Such a holistic strategy was proposed in the Draft Women Farmer's Entitlement Bill (2013) in India, which defined women as farmers, and sought equal entitlements to all resources and opportunities available to male farmers, whether land, water, credit or technology, alongside equal representation in decision-making around agricultural policies and programmes. Such legislation, if adopted and enforced, has the potential to break the symbolism of women as property, with access to landed property not conditional on their marital status or social position ${ }^{7}$, thereby transforming unequal gender relations across social institutions from the household to the state. The draft bill has however yet to become law.

An important dimension that needs serious policy attention is women's time burdens, especially in relation to unpaid care work, as this contributes to the intergenerational transfer of nutritional disadvantage ${ }^{19}$. Good quality local infrastructure including clean drinking water and clean energy are necessary, alongside public goods such as basic education and health ${ }^{51}$. Equally important is the need 
for high quality childcare to ensure feeding and care of the young child when the mother is working on the farm ${ }^{52,53}$. Apart from helping reduce and manage severe forms of malnutrition, creches can also help reduce women's dependency on extended family members, especially in-laws, who may engage in violence and other forms of control including denying women food ${ }^{54,10}$. The lack of attention to these services contributes to a perpetuation of both poor nutritional outcomes and gender inequality in South Asia.

Women's mobilization and collective action are critical to ensuring the enforcement of law and the implementation of gender-responsive policies and programmes, especially in the face of newer challenges posed by climate change, urbanization, male migration or changing aspirations on gender divisions of labour, resource control and decision-making. While outcomes are not guaranteed, such public action will go some way to tackling the problem of women's poorly defined rights, and in turn, the threats to their food, nutrition, and wider livelihood security, alongside keeping alive the pressure for gender equality and justice ${ }^{55}$.

\section{Key References}

1. Cornwall, A and J. Edwards (2015). Introduction: Beijing+20 - Where now for gender equality? IDS Bulletin 46(4): 1-8.

2. Global Hunger Index (GHI), 2019, accessed https://www.globalhungerindex.org/results.html on 22/10/19.

3. Smith, L. C and L.Haddad (2015) Reducing Child Undernutrition: Past Drivers and Priorities for the Post-MDG Era. World Development. 68: 180-204.

4. Ministry of Health and Family Welfare (MoHFW), Government of India, UNICEF and Population Council. 2019. Comprehensive National Nutrition Survey (CNNS) National Report. New Delhi.

5. WHO (2019) Delivered by Women, Led by Men: A Gender and Equity Analysis of the Global Health and Social Workforce. Human Resources for Health Observer Series No. 24. Geneva, World Health Organization.

6. Rao, N. (2017). Assets, Agency and Legitimacy: Towards a Relational Understanding of Gender Equality Policy and Practice. World Development. 95: 43-54.

7. Rao, N (2013) Rights, recognition and rape. Economic and Political Weekly. 48(7): 18-20.

8. Rao, N., Gazdar, H., Chanchani, D. and M. Ibrahim (2019) Women's agricultural work and nutrition in South Asia: From pathways to a cross-disciplinary, grounded analytical framework. Food Policy. 82: 50-62.

9. Usta, J., Makarem, N., and R. Habib (2013). Economic abuse in Lebanon: experiences and perceptions. Violence against women. 19: 356-375.

10. Lentz, E. C. (2018). Complicating narratives of women's food and nutrition insecurity: Domestic violence in rural Bangladesh. World Development. 104: 271-280.

11. Rao, N (2019) From abandonment to autonomy: gendered strategies for coping with climate change, Isiolo country, Kenya. Geoforum. 102: 27-37.

12. Bellows, A.C., Lemke, S., Jenderedjian, A and V. Scherbaum (2015). Violence as an unrecognized barrier to women's realization of their right to adequate food and nutrition: Case studies from Georgia and South Africa. Violence against women. 21(10): 1194-1217.

13. Chilton, M. M, Rabinowich, J.R and N. H. Woolf (2013) Very low food security in the USA is linked with exposure to violence. Public Health Nutrition. 17(1): 73-82.

14. García-Moreno, C., Jansen, H., Ellsberg, M., Heise, L and C. Watts (2005) WHO Multi-country Study on Women's Health and Domestic Violence against Women. Geneva. World Health Organisation.

15. Rao, N and A. Pervez (2019) Gender equality in India: New challenges confronting progress. In: Haque, T and D.N Reddy (eds.) India Social Development Report 2018: Rising Inequalities in 
India. New Delhi. Oxford University Press: 165-173.

16. International Institute for Population Sciences (IIPS) and ICF. 2017. National Family Health Survey (NFHS-4), 2015-16: India. Mumbai: IIPS.

17. Bellows, A.C (2003). Exposing violences: using women's human rights theory to reconceptualize food rights. Journal of Agricultural and Environmental Ethics. 16: 249-279.

18. Ackerson, L.K and S.V. Subramanian (2008) Domestic Violence and Chronic Malnutrition among Women and Children in India. American Journal of Epidemiology, 167(10): 1188-1196.

19. Chilton, M.M, Knowles, M. and S.L Bloom (2017) The intergenerational circumstances of household food insecurity and adversity. Journal of hunger and environmental nutrition. 12(2): 269-297.

20. National Nutrition Monitoring Bureau (NNMB). 2009. Diet and Nutritional Status of Tribal Population and prevalence of hypertension amongst adults: Report on second repeat survey. NNMB Technical Report No. 25. Hyderabad. National Institute of Nutrition (ICMR).

21. Menon, P, Mani, S and P.H. Nguyen (2017). How are India's districts doing on maternal, infant and young child nutrition? Insights from the National Family Health Survey - 4. POSHAN Date Note No. 1. New Delhi. International Food Policy Research Institute.

22. Rao, N and S. Raju (2019) Gendered time, seasonality and nutrition: Insights from two Indian districts. Feminist Economics. DOI: 10.1080/13545701.2019.1632470.

23. Johnston, D., Stevano, S., Malapit, H.J., Hull, E, and S. Kadiyala (2018) Time Use as an Explanation for the Agri-Nutrition Disconnect: Evidence from Rural Areas in Low and MiddleIncome Countries. Food Policy. 76: 8-18.

24. Harris, L.M (2009) Gender and emergent water governance: comparative overview of neoliberalized natures and gender dimensions of privatization, devolution and marketization. Gender, Place and Culture. 16(4): 387-408.

25. Mitra, A and N. Rao (2019). Contract Farming, Ecological Change and the Transformations of Reciprocal Gendered Social Relations in Eastern India. The Journal of Peasant Studies. DOI: 10.1080/03066150.2019.1683000.

26. NSSO (National Sample Survey Office). (2013). Household ownership and operational holdings in India. NSS $70^{\text {th }}$ Round. Government of India. Ministry of Statistics and Program Implementation. New Delhi.

27. Watts, M.J (1983). Silent Violence: Food, famine, and peasantry in Northern Nigeria. University of California Press. Berkeley.

28. Harriss-White, B (2005) Commercialisation, Commodification and Gender Relations in Postharvest Systems for Rice in South Asia. Economic and Political Weekly. June 18. Pp 2530-42.

29. Agarwal, B. (1985) Women and technological change in agriculture: The Asian and African experience. In: Ahmed, I (ed.) Technology and rural women. George Allen and Unwin, London: pp 67-150.

30. Swaminathan, M. S. (2016). National Policy for Farmers: Ten years later. Review of Agrarian Studies, 6(1): 133-144.

31. Djurfeldt, G., V. Athreya., et al. (2008) Agrarian change and social mobility in Tamil Nadu. Economic and Political Weekly 43(45): 50-61.

32. Swaminathan, M. and V. Prasad (2010) 'Maternity Entitlements: Past and Present', in Public Health Research Network, M.S. Swaminathan Research Foundation and Tamil Nadu Forum for Creche and Child Care Services (eds) Towards Universalisation of Maternity Entitlements: An Exploratory Case of Study of the Dr. Muthulakshmi Reddy Maternity Assistance Scheme, Tamil Nadu. New Delhi.

33. Rao, N and A. Mitra (2013). Migration, representations and social relations: experiences of Jharkhand labour to western Uttar Pradesh. Journal of Development Studies. 49(6): 846-860.

34. Rao, N (2012) Male 'providers' and female 'housewives: A gendered co-performance in rural North India. Development and Change, 43(5):1025-48. 
35. Springer, K.W, Hankivsky, O. and L.M.Bates (2012) Introduction. Gender and Health: Relational, intersectional, and biosocial approaches. Social Science and Medicine. 74: 1661-1666.

36. Shekhar, H. S (2015) The Adivasi will not dance. Speaking Tiger Books, New Delhi.

37. Kadiyala, S., Harris, J., Headey, D., Yosef, S. and S. Gillespie (2014) Agriculture and nutrition in India: mapping evidence to pathways. Annals of the New York Academy of Sciences, 1331 (1): 43-56.

38. Petesch, P., Smulovitz, C., and M. Walton (2005) Evaluating Empowerment: A Framework with Cases from Latin America. In Narayan, D (ed.) Measuring empowerment: Cross-disciplinary perspectives. The World Bank. Washington D.C. pp 39-68.

39. Chattopadhyay, R and E. Duflo (2004) Women as policymakers: evidence from a randomized policy experiment in India. Econometrica. 72(5): 1409-43.

40. Food and Agricultural Organization (2011) The state of food and agriculture 2010-2011. Women in agriculture: closing the gender gap for development. Rome: FAO.

41. Chowdhry, P (2004) Caste panchayats and the policing of marriage in Haryana: enforcing kinship and territorial exogamy. In: Gupta, D (ed.) Caste in question: Identity of hierarchy?. New Delhi. Sage. 1-42.

42. UN Women and RDI (2011) Gender and land tenure security: Challenges and barriers to women's entitlement to land in India. UN Women. New Delhi.

43. Agarwal, B. (1998) Widows vs daughters or widows as daughters: property, land and economic security in rural India. Modern Asian Studies, 32(1): 1-48.

44. Kelkar, G (2016). Between protest and policy: Women claim their right to agricultural land in rural China and India. Working Paper 10. Project When and Why to states respond to women's claims? Understanding gender egalitarian policy change in Asia. United Nations Research Institute for Social Development. Geneva. P 38.

45. Swaminathan, S. and India State-level Disease Burden Initiative Collaborators (2019) The burden of child and maternal malnutrition and trends in its indicators in the states of India: the Global Burden of Disease Study 1990-2017. The Lancet child and adolescent health. https://doi.org/10.1016/S2352-4642(19)30273-1.

46. Food and Agricultural Organization (1996) Rome declaration on world food security. Rome: FAO.

47. Jones, $S$ (1999) Singlehood for security: towards a review of the relative economic status of women and children in woman-led households. Society in Transition. 30: 13-27.

48. Connell, R.W (1987) Gender and power: society, the person and sexual politics. Palo Alto. Stanford University Press.

49. Sen, A. K. (1981) Poverty and famines: An essay on entitlement and deprivation. Oxford. Oxford University Press.

50. Elson, D (2017) Recognize, Reduce, and Redistribute Unpaid Care Work: How to Close the Gender Gap. New Labor forum. 26(2): 52-61.

51. Cavatorta, E., Shankar, B., \& Flores-Martinez, A. (2015). Explaining cross-state disparities in child nutrition in rural India. World Development, 76: 216-237.

52. Prasad, V., Sinha, D., Chatterjee, P., and R. K. Gope (2018) Outcomes of Children with Severe Acute Malnutrition in a Tribal Day-care Setting. Indian Pediatrics. 55 (February 15): 134-36. DOI: 10.1007/s13312-018-1246-z.

53. Gope, R.K., Tripathy, P, Prasad, V et al. (2019) Effects of participatory learning and action with women's groups, counselling through home visits and crèches on undernutrition among children under three years in eastern India: a quasi-experimental study. BMC Public Health. 19(962). https://doi.org/10.1186/s12889-019-7274-3.

54. Coffey, D., Khera, R., and D. Spears (2015) Intergenerational effects of women's status: 
Evidence from joint Indian households. Paper presented at the PAA Economic Demography Workshop, NEUDC, the Delhi School of Economics, UT Austin, Tufts, and Princeton.

55. Dreze, J and A. Sen (1989) Hunger and Public Action. Clarendon Press. Oxford.

\section{Acknowledgements}

This Perspective draws on several years of work in South Asia, particularly India. I am thankful to the many rural women and men, who have shared their lives and thoughts with me over the years.

Some of these ideas have been refined by my involvement with the DFID-funded Leveraging Agriculture for Nutrition in South Asia (LANSA) consortium (2013-2018) and the BBSRC-funded Transforming India's Green Revolution towards Sustainable Food Supplies (Tigr2ess: 2018-2021), and I wish to acknowledge their support. Finally, I thank the anonymous reviewers for their constructive comments and the editor for her encouragement to write this piece and editorial support.

Data Availability

All correspondence and request for materials should be addressed to the author.

Competing Interests

The author declares no competing interests. 